\title{
Necrostatin-1 Reduces Neurovascular Injury after Intracerebral Hemorrhage
}

\author{
Melanie D. King, Wittstatt A. Whitaker-Lea, James M. Campbell, \\ Cargill H. Alleyne Jr., and Krishnan M. Dhandapani \\ Department of Neurosurgery, Medical College of Georgia, Georgia Regents University, 1120 15th Street, Augusta, GA 30912, USA \\ Correspondence should be addressed to Krishnan M. Dhandapani; kdhandapani@gru.edu
}

Received 11 November 2013; Revised 24 January 2014; Accepted 27 January 2014; Published 6 March 2014

Academic Editor: Claudia Giampietri

Copyright (c) 2014 Melanie D. King et al. This is an open access article distributed under the Creative Commons Attribution License, which permits unrestricted use, distribution, and reproduction in any medium, provided the original work is properly cited.

\begin{abstract}
Intracerebral hemorrhage (ICH) is the most common form of hemorrhagic stroke, accounting for $15 \%$ of all strokes. ICH has the highest acute mortality and the worst long-term prognosis of all stroke subtypes. Unfortunately, the dearth of clinically effective treatment options makes ICH the least treatable form of stroke, emphasizing the need for novel therapeutic targets. Recent work by our laboratory identified a novel role for the necroptosis inhibitor, necrostatin-1, in limiting neurovascular injury in tissue culture models of hemorrhagic injury. In the present study, we tested the hypothesis that necrostatin-1 reduces neurovascular injury after collagenase-induced ICH in mice. Necrostatin-1 significantly reduced hematoma volume by $54 \%$ at $72 \mathrm{~h}$ after-ICH, as compared to either sham-injured mice or mice administered an inactive, structural analogue of necrostatin-1. Necrostatin-1 also limited cell death by $48 \%$, reduced blood-brain barrier opening by $51 \%$, attenuated edema development to sham levels, and improved neurobehavioral outcomes after ICH. These data suggest a potential clinical utility for necrostatin-1 and/or novel necroptosis inhibitors as an adjunct therapy to reduce neurological injury and improve patient outcomes after ICH.
\end{abstract}

\section{Introduction}

Spontaneous intracerebral hemorrhage (ICH) accounts for $\sim 15 \%$ of all strokes and induces a 30 -day mortality rate of $\sim 40 \%$ [1-5]. The rupture of small vessels damaged by chronic hypertension or amyloid angiopathy induces primary $\mathrm{ICH}$, creating a space-occupying hematoma within the brain parenchyma. Hematoma volume directly correlates with neurological deterioration and patient mortality $[2,6-9]$ and neurosurgical clot evacuation produces more favorable outcomes in subsets of ICH patients; however, many patients are not amenable to surgical intervention due to hematoma location or concurrent intraventricular hemorrhage [10]. As such, conservative management remains a clinical mainstay, reinforcing the notion that $\mathrm{ICH}$ is the least treatable form of strokes and stressing the need for novel therapeutic approaches.

Vascular injury and inflammatory activation are predictive markers of hematoma enlargement, development of vasogenic edema, and acute neurological deterioration [11,
12]. Apoptosis of cerebral endothelial cells increased bloodbrain barrier (BBB) permeability, vasogenic edema, and neurological impairment after hemorrhagic stroke [13, 14]. Furthermore, activation of the proinflammatory transcription factor, $\mathrm{NF} \kappa \mathrm{B}$, correlated with apoptotic cell death within perihematomal blood vessels after ICH [15]. Thus, a reduction in neurovascular injury may improve outcomes after ICH; however, the underlying mechanisms remain poorly defined and contribute to the lack of medical treatment options after $\mathrm{ICH}$.

Inflammation is a conserved immune response to tissue injury. Hemolysis of extravasated erythrocytes triggers the release of proinflammatory mediators in and around the hematoma core. Along these lines, inflammatory activation correlates with increased hematoma expansion, neurological deterioration, and a poor functional recovery after ICH [12, 15-17]. Notably, elevated plasma concentrations of the proinflammatory mediator, tumor necrosis factor- $\alpha$ (TNF- $\alpha$ ), clinically correlated with acute hematoma enlargement, edema development, and patient outcome following ICH [18-22]. 
Similarly, TNF- $\alpha$ expression was acutely increased within the perihematoma tissue using multiple species and models of experimental ICH [23-28]. Coupled with our finding that neurovascular injury directly correlated with TNF- $\alpha$ expression after $\mathrm{ICH}$ in mice, TNF- $\alpha$ may induce acute neurological injury after ICH; however, the mechanisms underlying TNF- $\alpha$-induced neurovascular injury after ICH remain poorly defined.

Recent evidence suggests that TNF- $\alpha$ induces necroptosis, a novel form of cell death that exhibits features of apoptosis, necrosis, and type 2 autophagic death [29-32]. Although the role of necroptotic cell death after ICH remains unexplored, we first reported that hemin, a hemoglobin oxidation byproduct that accumulates within intracranial hematomas [33], induced TNF- $\alpha$ expression and promoted necroptotic cell death in cultured astrocytes [34]. Receptor interacting protein kinase 1 (RIPK1) is a multifunctional protein kinase that interacts with TNF- $\alpha$ receptor (TNFR) to promote $\mathrm{NF} \kappa \mathrm{B}$ and to activate necroptotic cell death [3537]. Thus, RIPK1 may represent a novel therapeutic target after ICH. Herein, we hypothesized that necrostatin-1 (Nec1), a novel and highly selective RIPK1 inhibitor, improves neurological outcomes following ICH.

\section{Materials and Methods}

2.1. ICH Model. Animal studies were reviewed and approved by the Committee on Animal Use for Research and Education at Georgia Regents University (Protocol number 2008-0166), in compliance with NIH guidelines. Male CD-1 mice (810 weeks old; Charles River, Wilmington, MA, USA) were anesthetized with a cocktail of $8 \mathrm{mg} / \mathrm{kg}$ xylazine and $60 \mathrm{mg} / \mathrm{kg}$ ketamine. Throughout all surgical procedures, body temperature was maintained at $37^{\circ} \mathrm{C}$ by using a small-animal temperature controller (David Kopf Instruments, Tujunga, CA, USA). Mice were placed into a stereotactic frame and a $0.5 \mathrm{~mm}$ diameter burr hole was drilled over the parietal cortex, $2.2 \mathrm{~mm}$ lateral to the bregma. A 26-gauge Hamilton syringe, loaded with $0.04 \mathrm{U}$ of bacterial type IV collagenase in $0.5 \mu \mathrm{L}$ saline, was lowered $3 \mathrm{~mm}$ deep from the skull surface directly into the left striatum. The syringe was depressed at a rate of $450 \mathrm{~nL} / \mathrm{min}$ and left in place for 10 minutes after the procedure to prevent solution reflux and excess diffusion. Sham animals underwent the same surgical procedure, except that saline was stereotactically injected rather than collagenase. After the syringe was removed, bone wax was used to close the burr hole, the incision was surgically stapled, and mice were kept warm until recovery of the righting reflex. This entire procedure was detailed previously by our structural analog (Nec- $\left.1_{\text {inactive }}\right)$ (Tocris, Ballwin, MO, USA; see Figure 1), or saline (placebo) was administered via the intracerebroventricular (icv) route at the time of injury. This dose of Nec-1 and route of administration were based on previous studies showing efficacy in preclinical models of stroke and traumatic brain injury $[37,38]$.

2.2. Hematoma Volume. Hematoma volume was spectrophotometrically quantified by the QuantiChrom Hemoglobin

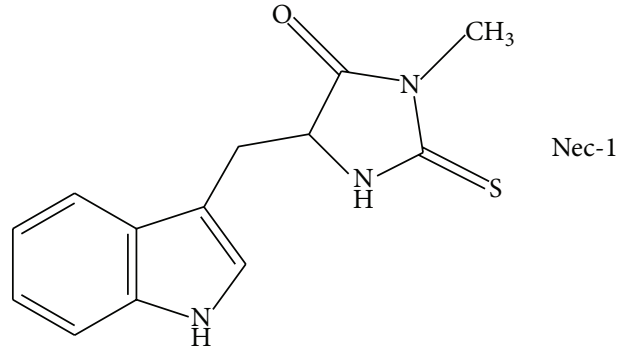

(a)

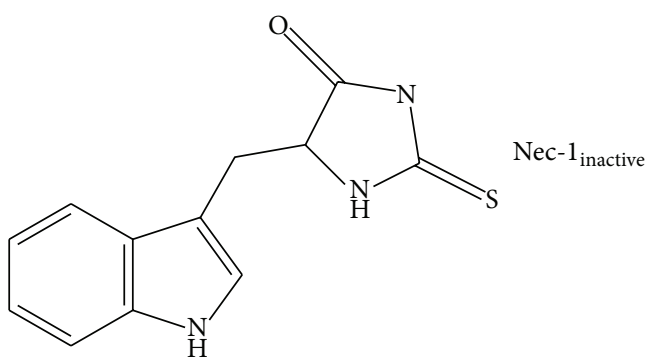

(b)

FIgURE 1: Chemical structures of Nec-1 and Nec- $1_{\text {inactive }}$.

Assay Kit (Bioassay Systems, Hayward, CA, USA), as per the manufacturer's recommendations and as routine to our laboratory [39]. The amount of hemoglobin in each hemisphere was calculated using the following: [(optical density of sample/optical density of calibrator) $* 100]$.

2.3. BBB Permeability. BBB permeability was quantified following administration of Evans blue $(20 \mathrm{mg} / \mathrm{mL}$ in PBS, i.v.) $2 \mathrm{~h}$ prior to sacrifice. Blood $(100 \mu \mathrm{L})$ was obtained by cardiac puncture and centrifuged, and then the plasma was diluted in N,N-Dimethylformamide $(1: 1000)$. Following perfusion with saline, brains were weighed, solubilized in $\mathrm{N}, \mathrm{N}$-Dimethylformamide, and then incubated at $78^{\circ} \mathrm{C}$ for $18 \mathrm{~h}$. Absorbance was then determined in brain and blood samples at $620 \mathrm{~nm}$ using a Synergy HT plate reader (BioTek, Winooski, VT, USA). The concentration of Evans blue $(\mu \mathrm{g} / \mu \mathrm{L})$ in each sample, a measure of BBB permeability, was calculated using a standard curve, and permeability was equal to [(Evans blue concentration of brain/weight of brain)/(Evans blue concentration of plasma/circulation time)], as reported previously by our group $[39,40]$.

2.4. Assessment of Cerebral Edema. Brain water content, an established measure of cerebral edema, was quantified in $2 \mathrm{~mm}$ coronal tissue sections of the ipsilateral or corresponding contralateral striatum, as routine to our laboratory [3942]. Tissue was immediately weighed (wet weight) and then dehydrated at $65^{\circ} \mathrm{C}$. Samples were reweighed $48 \mathrm{~h}$ later to obtain a dry weight. The percentage of water content in each sample was calculated as follows: $\%$ Brain water content = [((wet weight-dry weight)/wet weight $) * 100]$. 
2.5. RNA Isolation and $q R T-P C R$. Total RNA was isolated (SV RNA Isolation kit, Promega, Madison, WI, USA) and qRTPCR was performed on a Cepheid SmartCycler II (Cepheid, Sunnyvale, CA, USA) using a Superscript III Platinum SYBR Green One-Step qRT-PCR kit (Invitrogen, Carlsbad, CA, USA), as per our laboratory [34, 39, 41-43]. Product specificity was confirmed by melting curve analysis and visualization of a single, appropriately sized band on a $2 \%$ agarose gel. Gene expression levels were quantified using a cDNA standard curve and data was normalized to RPS3, a housekeeping gene that is unaffected by the experimental manipulations. Data is expressed as fold change versus sham.

2.6. Immunohistochemistry. Deeply anesthetized mice were perfused with saline followed by $4 \%$ paraformaldehyde in PBS. Brains were removed and postfixed in $4 \%$ paraformaldehyde overnight at $4{ }^{\circ} \mathrm{C}$ and then transferred into $30 \%$ sucrose. Tissue sections $(20 \mu \mathrm{m})$ were direct-mounted onto glass slides and stained using a primary antibody against glial fibrillary acidic protein (GFAP; Dako, 1:200), as detailed by our laboratory $[41,44]$. After labeling with an AlexaFluor tagged secondary antibody, immunoreactivity was determined using a Zeiss LSM510 confocal microscope.

\subsection{Propidium Iodide Staining. Propidium iodide (PI, $150 \mathrm{ng}$ )} was administered via tail vein five hours prior to sacrifice. Following tissue sectioning, brain sections were imaged by confocal microscopy. The number of PI positive cells was quantified by cell counts in three specified regions within the perihematomal regions. Counts were normalized to placebotreated mice after ICH.

2.8. Neurological Outcomes. Neurological injury was determined using a modified 24-point scale, as detailed previously by our laboratory and others $[39,40,45,46]$. This scale comprised six behavioral tests, each of which was graded from 0 (performs with no impairment) to 4 (severe impairment). A composite score was calculated as the sum of the grades on all six tests.

2.9. Statistical Analysis. One-way analysis of variance (ANOVA) followed by Student-Newman-Keuls or two-way ANOVA followed by Tukey's post hoc test was used for multiple group comparisons. Data are expressed as mean $+/-$ SEM. A $P$ value of $<0.05$ was considered to be significant.

\section{Results}

3.1. Necrostatin-1 Reduces Hematoma Volume after ICH. Administration of Nec-1 significantly reduced hematoma volume within the ipsilateral hemisphere at $72 \mathrm{~h}$ after ICH (Figure 2). Specifically, hemoglobin content was increased within the injured hemisphere from $26.5 \pm 2.6 \mathrm{mg} / \mathrm{dL}$ in sham-operated mice to $80.8 \pm 9.9 \mathrm{mg} / \mathrm{dL}$ following ICH $(P<$ 0.001 versus sham). Intrastriatal delivery of $\mathrm{Nec}-1$ at the time of ICH reduced hemispheric hemoglobin content to $37.3 \pm$ $8.1 \mathrm{mg} / \mathrm{dL}(P<0.001$ versus $\mathrm{ICH}$, not significantly different from sham). Administration of $\mathrm{Nec}-1_{\text {inactive }}$ also reduced

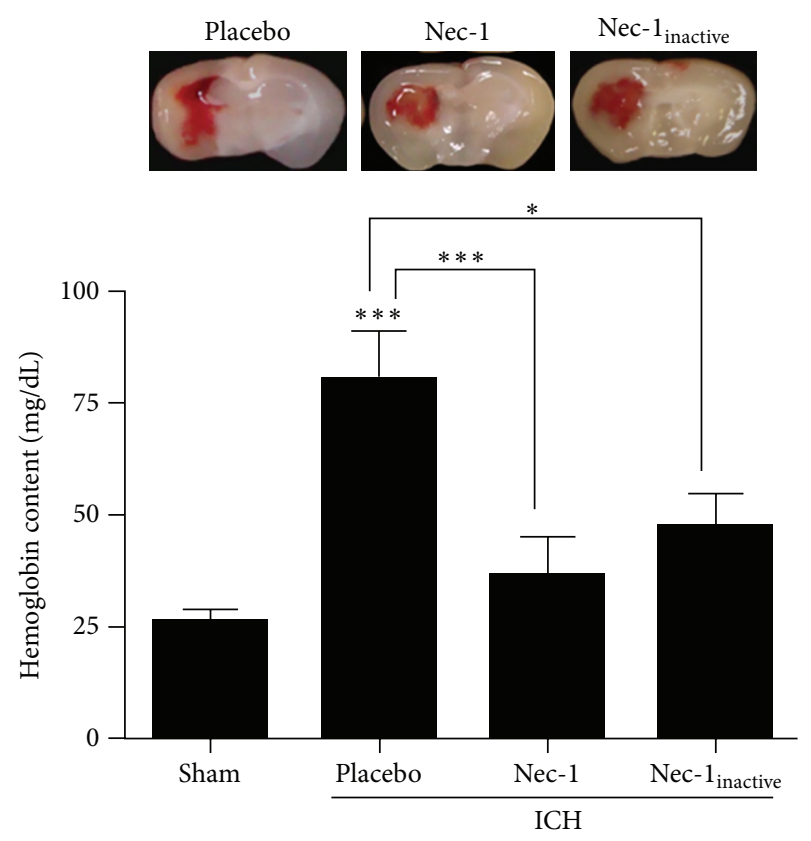

Figure 2: Nec-1 attenuates hematoma size after ICH. Nec-1 administration at the time of injury reduced hematoma size at $72 \mathrm{~h}$ after $\mathrm{ICH}$. Coronal brain images were prepared and digitally captured to visualize hematoma size (top panels). Hematoma volume was quantified by determining the hemoglobin content of each hemisphere at 72 hours after ICH (bottom panel). Data are expressed as mean \pm SEM $\left({ }^{*} P<0.05,{ }^{* * *} P<0.001 ; n=10-14\right.$ per group). Nec-1 and $\mathrm{Nec}-1_{\text {inactive }}$ were not significantly different from sham group.

hemoglobin content after ICH $(48.6 \pm 7.2 \mathrm{mg} / \mathrm{dL} ; P<0.05$ versus sham-, ICH-, and Nec-1-treated mice).

3.2. Cell Death Is Attenuated by Necrostatin-1 after ICH. The effect of Nec-1 on hematoma volume was mirrored by brain lesion volume, as assessed by hematoxylin and eosin staining (data not shown). Consistent with this finding, Nec-1 reduced the number of propidium iodide positive $\left(\mathrm{PI}^{+}\right)$cells within the perihematomal tissue by $48 \%$, as compared to ICH only mice $(P<0.01)$ (Figure 3$)$. In contrast, $\mathrm{Nec}-1_{\text {inactive }}$ reduced the number of $\mathrm{PI}^{+}$cells by $6.3 \%$ (not significantly different from placebo treated after ICH). Astrogliosis, a conserved response to brain injury [47, 48], was similarly reduced by Nec-1 treatment. Administration of Nec-1 reduced GFAP expression after ICH, as assessed by Western blotting and by immunohistochemistry, consistent with the attenuation of cellular injury (Figure 4). Coupled with our observation that $\mathrm{Nec}-1$ attenuated proinflammatory gene expression, including reduced TNF- $\alpha$ expression (MEK and KMD, unpublished observations), these findings suggest that necroptosis contributes to glial reactivity after ICH.

3.3. Necrostatin-1 Reduces Neurovascular Injury after ICH. Cerebral edema is a major cause of patient deterioration after ICH. Over the first $24 \mathrm{~h}$ after ICH, a significant increase in Evans blue extravasation, a sensitive measure of blood-brain 


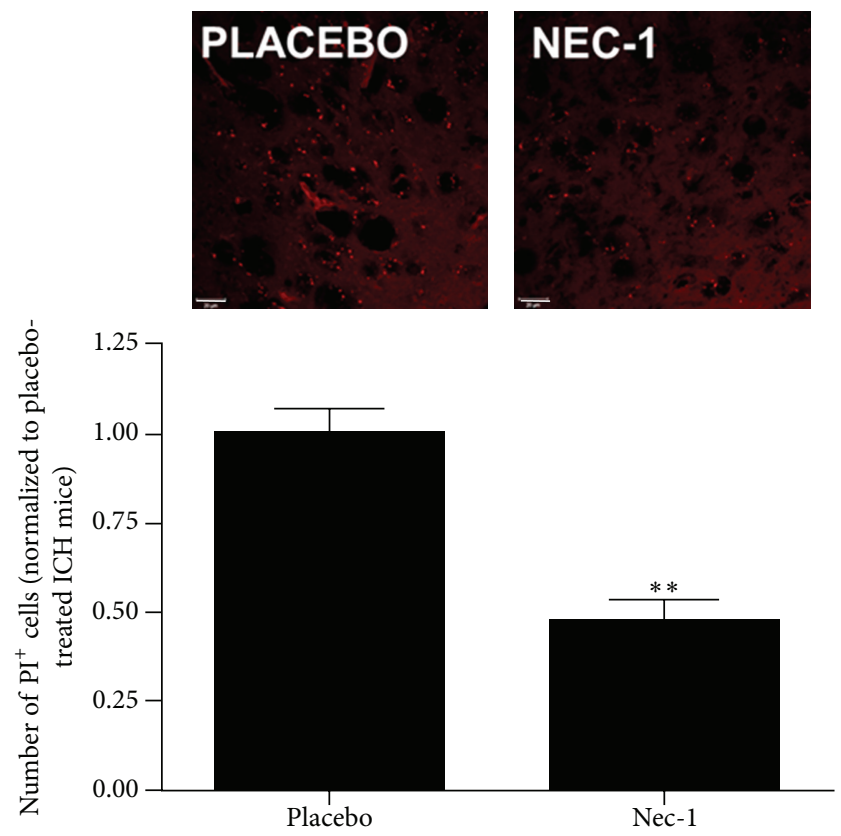

FIGURE 3: Nec-1 reduces cell death after ICH. Nec-1 administration at the time of ICH reduced perihematomal cell death, as assessed by PI staining. Top panels are representative images from placebo- or Nec-1-treated mice following ICH. Bottom panel depicts the quantification of PI staining following treatment with $\mathrm{Nec}-1$ or Nec- $1_{\text {inactive }}$. Cell counts were normalized to placebo-treated ICH mice. Data are expressed as mean $\pm \operatorname{SEM}\left({ }^{* *} P<0.01\right.$ versus placebo; $n=5$ per group $)$.

barrier disruption, is observed. This breach in the bloodbrain barrier was maximal between 3 and $12 \mathrm{~h}$ after injury, with spontaneous resealing observed at $24 \mathrm{~h}$. Administration of Nec-1 at the time of injury significantly reduced Evans blue extravasation at all time points (Figure 5). In contrast, Nec- $1_{\text {inactive }}$ did not significantly reduce blood-brain barrier opening at any time point, as compared to placebo-treated mice, suggesting a specific effect of Nec-1.

BBB opening contributes to the development of vasogenic edema; thus, the effect of $\mathrm{Nec}-1$ on edema development was next assessed. As was observed with Evans blue extravasation, Nec-1 reduced brain water content at all time points up to 5 days after ICH. The maximal effect of Nec-1 was noted at $24 \mathrm{~h}$ after ICH whereby brain water content was reduced from $80.3 \pm 0.2 \%$ in placebo-treated ICH mice to $76.8 \pm 0.4 \%$ following Nec-1 administration $(P<0.05$ versus placebo $)$ (Figure 6). As was observed with BBB opening, Nec- $1_{\text {inactive }}$ was without effect on brain edema development after ICH $(82.7 \pm 0.7 \% ; P<0.05$ versus Nec-1, not significantly different from placebo). No significant differences were observed between groups in the contralateral hemispheres.

3.4. Necrostatin-1 Improves Neurological Outcomes after ICH. In line with a reduction in cell death and reduced edema development, necrostatin-1 improved neurological outcomes after ICH. Specifically, necrostatin-1 significantly improved the outcomes using a 24-point scale across the first $72 \mathrm{~h}$ after injury, as compared to either placebo- or Nec- $1_{\text {inactive }}$-treated mice after ICH $\left(P<0.001\right.$ versus placebo-, Nec- $1_{\text {inactive }}{ }^{-}$ treated ICH mice) (Figure 7). Mice treated with necrostatin-1 were behaviorally not significantly different from shamoperated mice.

\section{Discussion}

$\mathrm{ICH}$, the most common form of hemorrhagic stroke, is associated with the highest mortality and the worst longterm neurological outcomes of all stroke subtypes [6]. Oneyear mortality rates are $>60 \%$ and of the $\sim 67,000$ Americans suffering an ICH annually, $<20 \%$ recover functional independence after six months $[1,2,49]$. Notably, the incidence of $\mathrm{ICH}$ is expected to double over the next several decades due to an aging population and to changes in racial demographics [3]. These data emphasize the devastating nature of $\mathrm{ICH}$ and indicate the need for improved treatment options.

Extravasation of erythrocytes creates a space-occupying hematoma within the brain parenchyma [6-9, 50-54]. Hematoma growth continues over the ensuing hours due to rebleeding from the ruptured arteriole, bleeding in surrounding compressed vessels, and/or local clotting defects after vessel rupture $[6,8,50]$. The persistent or recurrent bleeding exacerbates the mass lesion, induces local compression of the microvasculature, and contributes to subsequent neurovascular dysfunction $[3,6-8,50-53,55$, 56]. Hemolysis promotes spontaneous hematoma resolution; however, the concurrent production of hemoglobin degradation metabolites induces the release of proinflammatory mediators within and around the hematoma core. Along these lines, acute increases in TNF- $\alpha$ within the cerebrospinal fluid and plasma of spontaneous ICH patients correlated with patient mortality [22]. Furthermore, increased expression of 


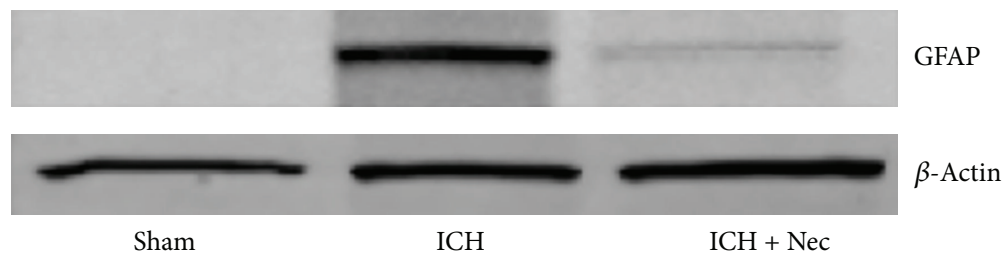

(a)
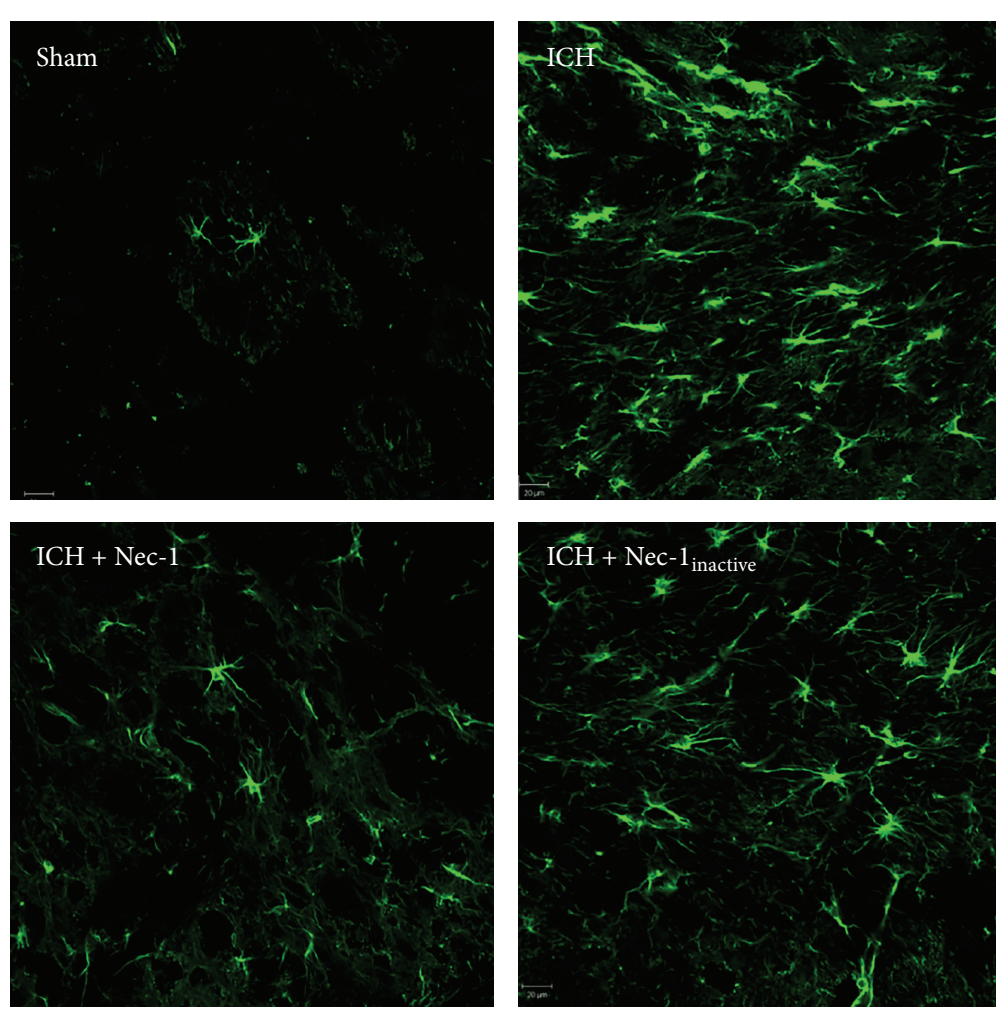

(b)

Figure 4: Effect of Nec-1 on ICH-induced reactive gliosis. Reactive astrogliosis was visualized by (a) Western blotting or (b) immunohistochemistry for glial fibrillary acidic protein (GFAP) at $72 \mathrm{~h}$ after ICH. GFAP immunoreactivity was increased and exhibited a characteristic stellate morphology after ICH. Administration of Nec-1 significantly reduced these effects whereas Nec- $1_{\text {inactive }}$ was without effect. Data are representative of 5 mice per group. Scale bar $=20 \mu \mathrm{m}$.

FasL and a corresponding decrease in s-Fas (an inhibitor of Fas activation) were detected in perihematomal brain tissue from ICH patients, as compared to control patients [57]. Although the functional significance of the inflammatory response remains incompletely understood, acute expression of both FasL and TNF- $\alpha$ was associated with cellular injury and with edema formation after ICH $[19,57,58]$. These findings suggest a detrimental role for the early inflammatory response after $\mathrm{ICH}$, yet the precise mechanisms whereby inflammation contributes to poor patient outcomes remain elusive.

Cell death is an important component of neurological injury after $\mathrm{ICH}$, although the form(s) of cell death after ICH remain poorly defined. Features of both apoptotic and necrotic cell death appear within six hours of injury in perihematomal neurons and glia in preclinical ICH models and in postmortem human studies, with peak injury noted at three days [59-62]. Similarly, loss of plasmalemma integrity, a phenotypic hallmark of necrotic cell death, increased over the first three days after collagenase-induced ICH in mice [63], further suggesting a prominent role for necrosis after ICH. In contrast to the view of necrosis as a passive, irreversible form of cell death, necroptosis is a newly described form of programmed necrosis that is induced by FasL and/or TNF- $\alpha$ [64]. As activation of the proinflammatory transcription factor, $\mathrm{NF} \kappa \mathrm{B}$, was associated with cell death after ICH, we hypothesized that necroptosis may contribute to neurovascular injury after a brain hemorrhage. To test this possibility, we investigated whether Nec-1, a novel small molecule inhibitor of necroptosis [64], could reduce neurological injury after ICH.

Herein, we identified a novel role for $\mathrm{Nec}-1$ in reducing cell death, attenuating hematoma expansion, limiting bloodbrain barrier disruption, and restricting edema development after ICH. Our findings, which are in agreement with a recent report showing Nec-1 on apoptotic and autophagic cell death 


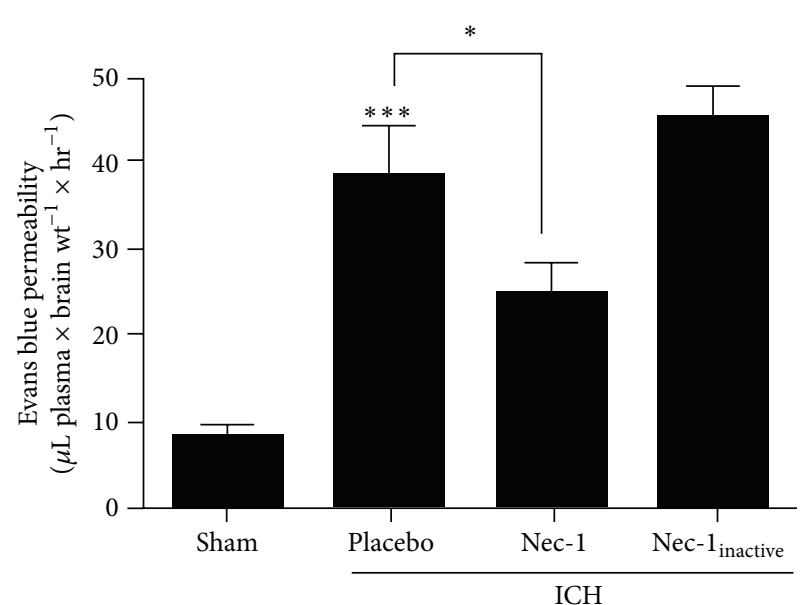

(a)

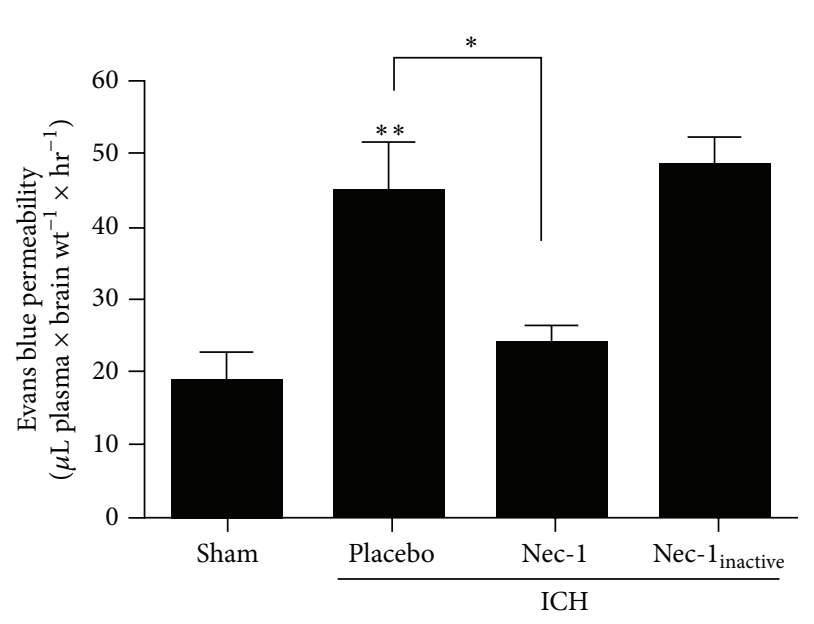

(b)

FIGURE 5: Nec-1 maintains blood-brain barrier integrity after ICH. Mice were administered $\mathrm{Nec}-1$ or $\mathrm{Nec}-1_{\text {inactive }}$ at the time of collagenase-induced ICH. Evans blue extravasation, a sensitive measure of BBB disruption, was assessed at (a) $3 \mathrm{~h}$ or (b) $12 \mathrm{~h}$ after $\mathrm{ICH}$. Data are expressed as mean \pm SEM and were analyzed by oneway ANOVA followed by Student- Newman-Keuls post hoc test $\left({ }^{* *} P<0.01,{ }^{* * *} P<0.001, n=7-8\right.$ per group $)$.

after collagenase-induced ICH [65], extend these findings using clinically relevant endpoints and suggest a potential role for targeting cell death pathways after ICH. Although the mechanism(s) whereby Nec-1 limited neurological injury were not explored in this study, it is notable that the biologically inactive, structural analog of Nec-1 did not exert the same protective effects of Nec-1 with respect to BBB opening, edema development, and behavioral outcomes; however, it is noteworthy that $\mathrm{Nec}-1_{\text {inactive }}$ attenuated hematoma volume to a similar magnitude as compared to Nec-1. Whereas these data suggest that the actions of Nec-1 may be selective rather than due to a nonspecific antioxidant effect, it remains unclear how Nec- $1_{\text {inactive }}$ selectively exerted this effect on hematoma volume. Notably, a recent report suggested that Nec- $1_{\text {inactive }}$ exerts biological activity on some necroptosis

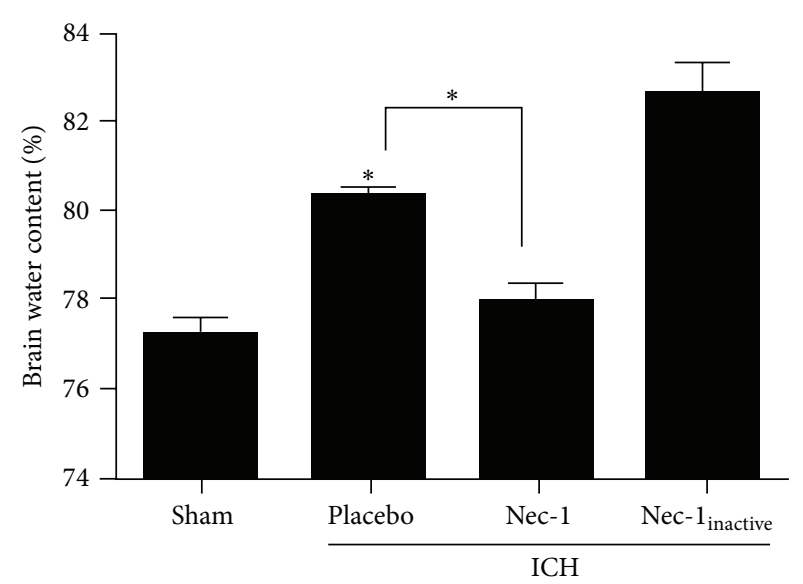

(a)

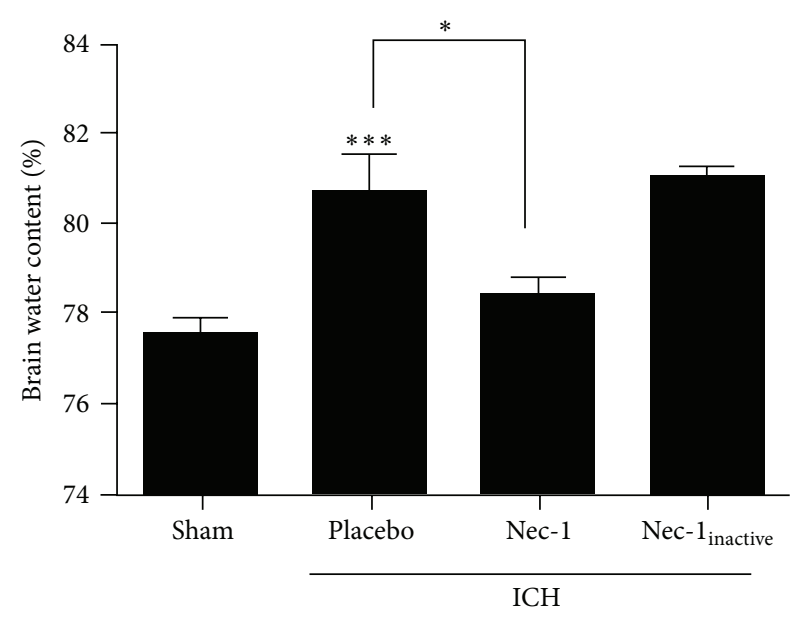

(b)

FIGURE 6: Nec-1 reduced edema development after ICH. Mice were administered Nec-1 or Nec- $1_{\text {inactive }}$ at the time of collagenaseinduced ICH. Brain water content, a measure of cerebral edema, was assessed in the ipsilateral hemisphere at (a) $24 \mathrm{~h}$ or (b) $72 \mathrm{~h}$ following ICH. Comparisons within each hemisphere between different treatment groups were done using a one-way ANOVA followed by Student-Newman-Keuls post hoc test $\left({ }^{*} P<0.05\right.$, $\left.{ }^{* * *} P<0.001\right)$. Data are expressed as mean \pm SEM from 10 mice per group.

assays and sensitizes mice to lethality during systemic inflammatory response syndrome [66]. These interesting results suggest that caution should be taken in the use of $\mathrm{Nec}-1_{\text {inactive }}$ as a true biologically inactive control to $\mathrm{Nec}-1$.

Receptor interacting protein 1 (RIP1), the proposed molecular target of $\mathrm{Nec}-1$ [36], is a serine/threonine protein kinase implicated in $\mathrm{NF} \kappa \mathrm{B}$ activation as well as in the initiation of necroptotic cell death [67]. Inflammatory activation at the time of admission was associated with early neurological deterioration in $\mathrm{ICH}$ patients [12] and $\mathrm{NF} \kappa \mathrm{B}$ activation was sustained over the first several days in a preclinical ICH model [17]. We and others reported that NF $\kappa$ B activation stimulates the expression of inflammatory mediators 


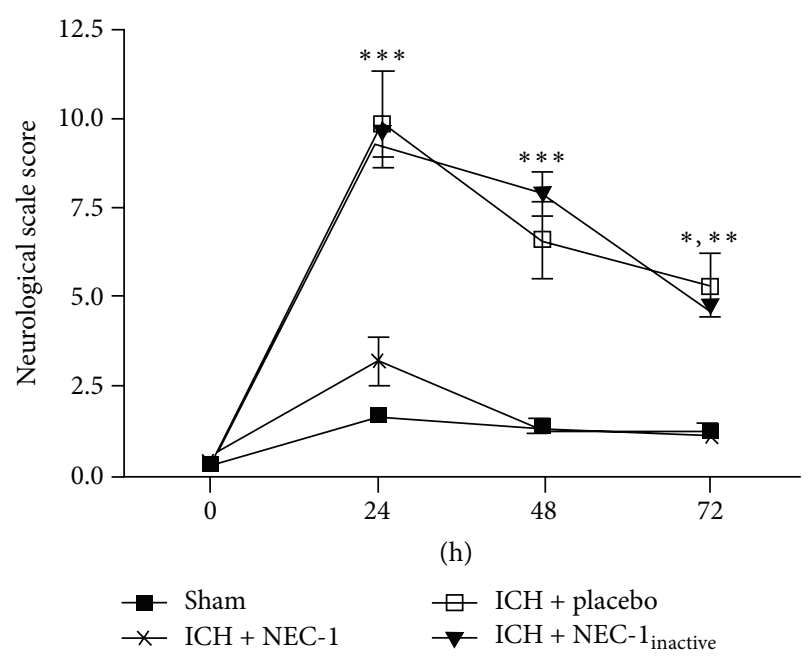

FIgURE 7: Nec-1 improves neurological outcome after ICH. Mice were administered $\mathrm{Nec}-1$ or Nec- $1_{\text {inactive }}$ at the time of collagenaseinduced ICH. Neurological outcomes were assessed at $24 \mathrm{~h}, 48 \mathrm{~h}$, or $72 \mathrm{~h}$ following sham or ICH. Data are expressed as mean $\pm \operatorname{SEM}(n=$ 10/group) and were analyzed using a repeated measures ANOVA followed by Bonferroni's post hoc test $\left({ }^{*} P<0.05,{ }^{* *} P<0.01\right.$, $\left.{ }^{* * *} P<0.001\right)$.

associated with necroptosis (e.g., TNF- $\alpha$ ), induces bloodbrain barrier permeability, increases edema development, and exacerbates neurobehavioral deficits after experimental $\mathrm{ICH}[15,17,39]$. Furthermore, we reported that the $\mathrm{NF} \kappa \mathrm{B}$ inhibitor, curcumin, promoted hematoma resolution and improved neurological outcomes after collagenase-induced ICH in mice [39]. Taken together, these results raise the unexplored possibility that RIP1 mediates acute neurological injury after ICH. Future work by our laboratory will characterize this interesting mechanism in further detail.

Nuclear blebbing and karyorrhexis were observed in glial cells within the white matter after intraventricular hemorrhage in preterm infants [68]. Astrocytic loss temporally preceded vascular injury after experimental ICH $[28,62]$ and focal astrocyte loss increased microvascular damage and induced transient $\mathrm{BBB}$ opening [69]. Although the cellular targets of Nec-1 after ICH were beyond the scope of the present study, these findings raise the possibility that the beneficial effects of Nec-1 observed herein may involve, at least in part, maintenance of glial function. Astrocytes are the primary source of the nonenzymatic antioxidant, glutathione, within the brain. We first reported that hemin rapidly depleted intracellular glutathione and induced caspase-independent cell death in murine astrocytes via an inflammatory mechanism [34]. Interestingly, this cellular injury was reversed by $\mathrm{Nec}-1$, suggesting a role for necroptosis after hemorrhagic injury [34]. Our finding is consistent with a subsequent report demonstrating that glutathione depletion enhanced the release of neurotoxic substances, including TNF- $\alpha$ from human astrocytes [70]. Similarly, Nec-1 prevented glutamate-induced glutathione depletion and caspase-independent cytotoxicity in HT-22 cells [71]. Coupled with our recent finding that astrocytederived glutathione reduced hemorrhagic injury in cerebral microvessels [72], Nec-1 may improve neurological outcomes by limiting astrocytic dysfunction.

Necroptosis is a novel form of programmed cell death that is initiated by proinflammatory mediators, such as TNF- $\alpha$. The model of ICH utilized in this study involves the intrastriatal injection of bacterial collagenase. Although this model best recapitulates the spontaneous intracerebral bleeding and evolving hematoma expansion observed in patients, collagenase may induce an exaggerated inflammatory response. Thus, the beneficial effects of Nec-1 may be overestimated. Nonetheless, cells exhibiting both apoptotic and/or necrotic phenotypes characteristic of necroptosis are observed in postmortem human brain sections, suggesting the validity of the protection observed in this study. Another limitation of the present study is that the mechanisms of Nec1 protection remain undetermined. Although regarded as a highly specific RIP1 inhibitor [36], several in vitro studies suggest a possible direct antioxidant role for Nec-1. Furthermore, Nec-1 also may block indoleamine-2,3-dioxygenase (IDO), which catabolizes tryptophan into kynurenine. The inclusion of Nec- $1_{\text {inactive }}$ is consistent with a selective effect of Nec1 as this analogue does not reportedly exhibit antioxidant activity nor does it inhibit mouse IDO [73], although a recent conflicting report suggests that $\mathrm{Nec}-1_{\text {inactive }}$ may attenuate human IDO activity [66]. Thus, the possibility that some or all of the beneficial actions of Nec-1 are mediated via RIP1independent mechanisms after ICH cannot be excluded. Future work by our laboratory will further characterize the specific therapeutic role of RIP1 targeting after brain hemorrhage. Regardless of the precise cellular mechanism, these studies suggest a novel protective role for $\mathrm{Nec}-1$ after $\mathrm{ICH}$.

\section{Conclusions}

The necroptosis inhibitor, Nec-1, reduced neurovascular injury and improved outcomes when administered at the time of injury in a preclinical model of ICH. These data suggest that therapeutic targeting of programmed necrosis may improve patient outcomes after a brain hemorrhage. Future work with more selective necroptosis inhibitors will establish the therapeutic window for improving neurovascular outcomes after ICH, providing a framework for potential clinical translation of these findings.

\section{Conflict of Interests}

The authors declare that there is no conflict of interests regarding the publication of this paper.

\section{Acknowledgments}

This work was supported by Grants from the National Institute of Health (NS065172, NS075774, and NS084228) and from the American Heart Association (BGIA2300135) to Krishnan M. Dhandapani. 


\section{References}

[1] M. S. Dennis, J. P. S. Burn, P. A. G. Sandercock, J. M. Bamford, D. T. Wade, and C. P. Warlow, "Long-term survival after first-ever stroke: the Oxfordshire Community Stroke Project," Stroke, vol. 24, no. 6, pp. 796-800, 1993.

[2] J. M. Gebel Jr., E. C. Jauch, T. G. Brott et al., "Relative edema volume is a predictor of outcome in patients with hyperacute spontaneous intracerebral hemorrhage," Stroke, vol. 33, no. 11, pp. 2636-2641, 2002.

[3] F. Rincon and S. A. Mayer, "Novel therapies for intracerebral hemorrhage," Current Opinion in Critical Care, vol. 10, no. 2, pp. 94-100, 2004.

[4] C. Weimar, C. Weber, M. Wagner et al., "Management patterns and health care use after intracerebral hemorrhage: a cost-ofillness study from a societal perspective in Germany," Cerebrovascular Diseases, vol. 15, no. 1-2, pp. 29-36, 2003.

[5] M. S. Dennis, "Outcome after brain haemorrhage," Cerebrovascular Diseases, vol. 16, supplement 1, pp. 9-13, 2003.

[6] A. I. Qureshi, S. Tuhrim, J. P. Broderick, H. H. Batjer, H. Hondo, and D. F. Hanley, "Spontaneous intracerebral hemorrhage," The New England Journal of Medicine, vol. 344, no. 19, pp. 1450-1460, 2001.

[7] G. A. Christoforidis, A. Slivka, Y. Mohammad, C. Karakasis, B. Avutu, and M. Yang, "Size matters: hemorrhage volume as an objective measure to define significant intracranial hemorrhage associated with thrombolysis," Stroke, vol. 38, no. 6, pp. 17991804, 2007.

[8] M. E. Fewel, B. G. Thompson Jr., and J. T. Hoff, "Spontaneous intracerebral hemorrhage: a review," Neurosurgical Focus, vol. 15, no. 4, p. E1, 2003.

[9] P. D. Lyden, A. Shuaib, K. R. Lees et al., "Safety and tolerability of NXY-059 for acute intracerebral hemorrhage: the CHANT trial," Stroke, vol. 38, no. 8, pp. 2262-2269, 2007.

[10] A. D. Mendelow, B. A. Gregson, H. M. Fernandes et al., "Early surgery versus initial conservative treatment in patients with spontaneous supratentorial intracerebral haematomas in the International Surgical Trial in Intracerebral Haemorrhage (STICH): a randomised trial," The Lancet, vol. 365, no. 9457, pp. 387-397, 2005.

[11] Y. Silva, R. Leira, J. Tejada, J. M. Lainez, J. Castillo, and A. Dávalos, "Molecular signatures of vascular injury are associated with early growth of intracerebral hemorrhage," Stroke, vol. 36, no. 1, pp. 86-91, 2005.

[12] R. Leira, A. Dávalos, Y. Silva et al., "Early neurologic deterioration in intracerebral hemorrhage: predictors and associated factors," Neurology, vol. 63, no. 3, pp. 461-467, 2004.

[13] T. Doczi, "The pathogenetic and prognostic significance of blood-brain barrier damage at the acute stage of aneurysmal subarachnoid haemorrhage. Clinical and experimental studies," Acta Neurochirurgica, vol. 77, no. 3-4, pp. 110-132, 1985.

[14] S. Park, M. Yamaguchi, C. Zhou, J. W. Calvert, J. Tang, and J. H. Zhang, "Neurovascular protection reduces early brain injury after subarachnoid hemorrhage," Stroke, vol. 35, no. 10, pp. 24122417, 2004.

[15] S. L. Hickenbottom, J. C. Grotta, R. Strong, L. A. Denner, and J. Aronowski, "Nuclear factor- $\kappa \mathrm{B}$ and cell death after experimental intracerebral hemorrhage in rats," Stroke, vol. 30, no. 11, pp. 2472-2478, 1999.

[16] N. Platt, R. P. da Silva, and S. Gordon, "Recognizing death: the phagocytosis of apoptotic cells," Trends in Cell Biology, vol. 8, no. 9, pp. 365-372, 1998.
[17] X. Zhao, Y. Zhang, R. Strong, J. Zhang, J. C. Grotta, and J. Aronowski, "Distinct patterns of intracerebral hemorrhageinduced alterations in NF- $\kappa \mathrm{B}$ subunit, iNOS, and COX-2 expression," Journal of Neurochemistry, vol. 101, no. 3, pp. 652663, 2007.

[18] J. S. Kim, S. S. Yoon, Y. H. Kim, and J. S. Ryu, "Serial measurement of interleukin-6, transforming growth factor- $\beta$, and S-100 protein in patients with acute stroke," Stroke, vol. 27, no. 9, pp. 1553-1557, 1996.

[19] J. Castillo, A. Dávalos, J. Álvarez-Sabín et al., "Molecular signatures of brain injury after intracerebral hemorrhage," Neurology, vol. 58 , no. 4, pp. 624-629, 2002.

[20] T. Dziedzic, S. Bartus, A. Klimkowicz, M. Motyl, A. Slowik, and A. Szczudlik, "Intracerebral hemorrhage triggers interleukin-6 and interleukin-10 release in blood," Stroke, vol. 33, no. 9, pp. 2334-2335, 2002.

[21] C. Woiciechowsky, B. Schöning, J. Cobanov, W. R. Lanksch, H.D. Volk, and W.-D. Döcke, "Early IL6 plasma concentrations correlate with severity of brain injury and pneumonia in braininjured patients," Journal of Trauma, vol. 52, no. 2, pp. 339-345, 2002.

[22] H.-Y. Fang, W.-J. Ko, and C.-Y. Lin, "Inducible heat shock protein 70 , interleukin-18, and tumor necrosis factor alpha correlate with outcomes in spontaneous intracerebral hemorrhage," Journal of Clinical Neuroscience, vol. 14, no. 5, pp. 435441, 2007.

[23] J. Aronowski and C. E. Hall, "New horizons for primary intracerebral hemorrhage treatment: experience from preclinical studies," Neurological Research, vol. 27, no. 3, pp. 268-279, 2005.

[24] M. Mayne, W. Ni, H. J. Yan et al., "Antisense oligodeoxynucleotide inhibition of tumor necrosis factor- $\alpha$ expression is neuroprotective after intracerebral hemorrhage," Stroke, vol. 32, no. 1, pp. 240-248, 2001.

[25] G. Xi, Y. Hua, R. F. Keep, J. G. Younger, and J. T. Hoff, "Systemic complement depletion diminishes perihematomal brain edema in rats," Stroke, vol. 32, no. 1, pp. 162-167, 2001.

[26] A. Lu, Y. Tang, R. Ran, T. L. Ardizzone, K. R. Wagner, and F. R. Sharp, "Brain genomics of intracerebral hemorrhage," Journal of Cerebral Blood Flow and Metabolism, vol. 26, no. 2, pp. 230-252, 2006.

[27] K. R. Wagner, S. Beiler, C. Beiler et al., "Delayed profound local brain hypothermia markedly reduces interleukin- $1 \beta$ gene expression and vasogenic edema development in a porcine model of intracerebral hemorrhage," Acta Neurochirurgica. Supplement, vol. 96, pp. 177-182, 2006.

[28] J. K. Wasserman, X. Zhu, and L. C. Schlichter, "Evolution of the inflammatory response in the brain following intracerebral hemorrhage and effects of delayed minocycline treatment," Brain Research, vol. 1180, no. 1, pp. 140-154, 2007.

[29] G. Kroemer, L. Galluzzi, P. Vandenabeele et al., "Classification of cell death: recommendations of the Nomenclature Committee on Cell Death 2009," Cell Death and Differentiation, vol. 16, no. 1, pp. 3-11, 2009.

[30] L. Galluzzi and G. Kroemer, "Necroptosis: a specialized pathway of programmed necrosis," Cell, vol. 135, no. 7, pp. 1161-1163, 2008.

[31] J. Hitomi, D. E. Christofferson, A. Ng et al., "Identification of a molecular signaling network that regulates a cellular necrotic cell death pathway," Cell, vol. 135, no. 7, pp. 1311-1323, 2008.

[32] C. Kitanaka and Y. Kuchino, "Caspase-independent programmed cell death with necrotic morphology," Cell Death and Differentiation, vol. 6, no. 6, pp. 508-515, 1999. 
[33] P. B. Letarte, K. Lieberman, K. Nagatani, R. A. Haworth, G. B. Odell, and T. A. Duff, "Hemin: levels in experimental subarachnoid hematoma and effects on dissociated vascular smooth-muscle cells," Journal of Neurosurgery, vol. 79, no. 2, pp. 252-255, 1993.

[34] M. D. Laird, C. Wakade, C. H. Alleyne Jr., and K. M. Dhandapani, "Hemin-induced necroptosis involves glutathione depletion in mouse astrocytes," Free Radical Biology and Medicine, vol. 45, no. 8, pp. 1103-1114, 2008.

[35] M. A. Kelliher, S. Grimm, Y. Ishida, F. Kuo, B. Z. Stanger, and P. Leder, "The death domain kinase RIP mediates the TNFinduced NF- $\kappa$ B signal," Immunity, vol. 8, no. 3, pp. 297-303, 1998.

[36] A. Degterev, J. Hitomi, M. Germscheid et al., "Identification of RIP1 kinase as a specific cellular target of necrostatins," Nature Chemical Biology, vol. 4, no. 5, pp. 313-321, 2008.

[37] A. Degterev, Z. Huang, M. Boyce et al., "Chemical inhibitor of nonapoptotic cell death with therapeutic potential for ischemic brain injury," Nature Chemical Biology, vol. 1, no. 2, pp. 112-119, 2005.

[38] Z. You, S. I. Savitz, J. Yang et al., "Necrostatin-1 reduces histopathology and improves functional outcome after controlled cortical impact in mice," Journal of Cerebral Blood Flow and Metabolism, vol. 28, no. 9, pp. 1564-1573, 2008.

[39] M. D. King, D. J. McCracken, F. M. Wade, S. E. Meiler, C. H. Alleyne Jr., and K. M. Dhandapani, "Attenuation of hematoma size and neurological injury with curcumin following intracerebral hemorrhage in mice: laboratory investigation," Journal of Neurosurgery, vol. 115, no. 1, pp. 116-123, 2011.

[40] M. D. King, C. H. Alleyne Jr., and K. M. Dhandapani, “TNFalpha receptor antagonist, R-7050, improves neurological outcomes following intracerebral hemorrhage in mice," Neuroscience Letters, vol. 542, pp. 92-96, 2013.

[41] D. E. Kimbler, J. Shields, N. Yanasak, J. R. Vender, and K. M. Dhandapani, "Activation of P2X7 promotes cerebral edema and neurological injury after traumatic brain injury in mice," PLoS ONE, vol. 7, no. 7, Article ID e41229, 2012.

[42] M. D. Laird, S. Sukumari-Ramesh, A. E. B. Swift, S. E. Meiler, J. R. Vender, and K. M. Dhandapani, "Curcumin attenuates cerebral edema following traumatic brain injury in mice: a possible role for aquaporin-4?" Journal of Neurochemistry, vol. 113, no. 3, pp. 637-648, 2010.

[43] C. Wakade, M. D. King, M. D. Laird, C. H. Alleyne Jr., and K. M. Dhandapani, "Curcumin attenuates vascular inflammation and cerebral vasospasm after subarachnoid hemorrhage in mice," Antioxidants and Redox Signaling, vol. 11, no. 1, pp. 35-45, 2009.

[44] S. Sukumari-Ramesh, C. H. Alleyne Jr., and K. M. Dhandapani, "Astrocyte-specific expression of survivin after intracerebral hemorrhage in mice: a possible role in reactive gliosis?" Journal of Neurotrauma, vol. 29, no. 18, pp. 2798-2804, 2012.

[45] G. A. Rosenberg, S. Mun-Bryce, M. Wesley, and M. Kornfeld, "Collagenase-induced intracerebral hemorrhage in rats," Stroke, vol. 21, no. 5, pp. 801-807, 1990.

[46] W. Clark, L. Gunion-Rinker, N. Lessov, and K. Hazel, "Citicoline treatment for experimental intracerebral hemorrhage in mice," Stroke, vol. 29, no. 10, pp. 2136-2140, 1998.

[47] L. F. Eng and R. S. Ghirnikar, "GFAP and astrogliosis," Brain Pathology, vol. 4, no. 3, pp. 229-237, 1994.

[48] M. V. Sofroniew, "Reactive astrocytes in neural repair and protection," Neuroscientist, vol. 11, no. 5, pp. 400-407, 2005.
[49] J. Broderick, S. Connolly, E. Feldmann et al., "Guidelines for the management of spontaneous intracerebral hemorrhage in adults: 2007 update: a guideline from the American Heart Association/American Stroke Association Stroke Council, High Blood Pressure Research Council, and the Quality of Care and Outcomes in Research Interdisciplinary Working Group," Stroke, vol. 38, no. 6, pp. 2001-2023, 2007.

[50] D. L. Labovitz and R. L. Sacco, "Intracerebral hemorrhage: update," Current Opinion in Neurology, vol. 14, no. 1, pp. 103108, 2001.

[51] J. Wu, Y. Hua, R. F. Keep, T. Nakamura, J. T. Hoff, and G. Xi, "Iron and iron-handling proteins in the brain after intracerebral hemorrhage," Stroke, vol. 34, no. 12, pp. 2964-2969, 2003.

[52] D. Davalos, J. Grutzendler, G. Yang et al., "ATP mediates rapid microglial response to local brain injury in vivo," Nature Neuroscience, vol. 8, no. 6, pp. 752-758, 2005.

[53] L. P. Wang, F. Li, X. Shen, and J. Z. Tsien, “Conditional knockout of NMDA receptors in dopamine neurons prevents nicotineconditioned place preference," PLOS ONE, vol. 5, no. 1, Article ID e8616, 2010.

[54] S. M. Davis, J. Broderick, M. Hennerici et al., "Hematoma growth is a determinant of mortality and poor outcome after intracerebral hemorrhage," Neurology, vol. 66, no. 8, pp. 11751181, 2006.

[55] M. R. McLaughlin and D. W. Marion, "Cerebral blood flow and vasoresponsivity within and around cerebral contusions," Journal of Neurosurgery, vol. 85, no. 5, pp. 871-876, 1996.

[56] D. G. Nehls, A. D. Mendelow, D. I. Graham, E. J. Sinar, G. M. Teasdale, and R. R. Smith, "Experimental intracerebral hemorrhage: progression of hemodynamic changes after production of a spontaneous mass lesion," Neurosurgery, vol. 23, no. 4, pp. 439-444, 1988.

[57] P. Delgado, E. Cuadrado, A. Rosell et al., "Fas system activation in perihematomal areas after spontaneous intracerebral hemorrhage," Stroke, vol. 39, no. 6, pp. 1730-1734, 2008.

[58] Y. Hua, J. Wu, R. F. Keep, T. Nakamura, J. T. Hoff, and G. Xi, "Tumor necrosis factor-alpha increases in the brain after intracerebral hemorrhage and thrombin stimulation," Neurosurgery, vol. 58, no. 3, pp. 542-550, 2006.

[59] A. P. Nguyen, H. D. Huynh, S. B. Sjovold, and F. Colbourne, "Progressive brain damage and alterations in dendritic arborization after collagenase-induced intracerebral hemorrhage in rats," Current Neurovascular Research, vol. 5, no. 3, pp. 171-177, 2008.

[60] K. Matsushita, W. Meng, X. Wang et al., "Evidence for apoptosis after intracerebral hemorrhage in rat striatum," Journal of Cerebral Blood Flow and Metabolism, vol. 20, no. 2, pp. 396-404, 2000.

[61] A. I. Qureshi, M. F. Suri, P. T. Ostrow et al., "Apoptosis as a form of cell death in intracerebral hemorrhage," Neurosurgery, vol. 52, no. 5, pp. 1041-1047, 2003.

[62] C. Gong, N. Boulis, J. Qian, D. E. Turner, J. T. Hoff, and R. F. Keep, "Intracerebral hemorrhage-induced neuronal death," Neurosurgery, vol. 48, no. 4, pp. 875-883, 2001.

[63] X. Zhu, L. Tao, E. Tejima-Mandeville et al., "Plasmalemma permeability and necrotic cell death phenotypes after intracerebral hemorrhage in mice," Stroke, vol. 43, no. 2, pp. 524-531, 2012.

[64] D. E. Christofferson and J. Yuan, "Necroptosis as an alternative form of programmed cell death," Current Opinion in Cell Biology, vol. 22, no. 2, pp. 263-268, 2010. 
[65] P. Chang, W. Dong, M. Zhang et al., "Anti-necroptosis chemical necrostatin-1 can also suppress apoptotic and autophagic pathway to exert neuroprotective effect in mice intracerebral hemorrhage model," Journal of Molecular Neuroscience, vol. 52, no. 2, pp. 242-249, 2014.

[66] N. Takahashi, L. Duprez, S. Grootjans et al., "Necrostatin-1 analogues: critical issues on the specificity, activity and in vivo use in experimental disease models," Cell Death \& Disease, vol. 3, article e437, 2012.

[67] W. Declercq, T. Vanden Berghe, and P. Vandenabeele, "RIP kinases at the crossroads of cell death and survival," Cell, vol. 138, no. 2, pp. 229-232, 2009.

[68] S. Chamnanvanakij, L. R. Margraf, D. Burns, and J. M. Perlman, "Apoptosis and white matter injury in preterm infants," Pediatric and Developmental Pathology, vol. 5, no. 2, pp. 184-189, 2002.

[69] C. L. Willis, C. C. Nolan, S. N. Reith et al., "Focal astrocyte loss is followed by microvascular damage, with subsequent repair of the blood-brain barrier in the apparent absence of direct astrocytic contact," Glia, vol. 45, no. 4, pp. 325-337, 2004.

[70] M. Lee, T. Cho, N. Jantaratnotai, Y. T. Wang, E. McGeer, and P. L. McGeer, "Depletion of GSH in glial cells induces neurotoxicity: relevance to aging and degenerative neurological diseases," The FASEB Journal, vol. 24, no. 7, pp. 2533-2545, 2010.

[71] X. Xu, C. C. Chua, J. Kong et al., "Necrostatin-1 protects against glutamate-induced glutathione depletion and caspaseindependent cell death in HT-22 cells," Journal of Neurochemistry, vol. 103, no. 5, pp. 2004-2014, 2007.

[72] S. Sukumari-Ramesh, M. D. Laird, N. Singh, J. R. Vender, C. H. Alleyne, and K. M. Dhandapani, "Astrocyte-derived glutathione attenuates hemin-induced apoptosis in cerebral microvascular cells," Glia, vol. 58, no. 15, pp. 1858-1870, 2010.

[73] A. Degterev, J. L. Maki, and J. Yuan, "Activity and specificity of necrostatin-1, small-molecule inhibitor of RIP1 kinase," Cell Death and Differentiation, vol. 20, no. 2, article 366, 2013. 

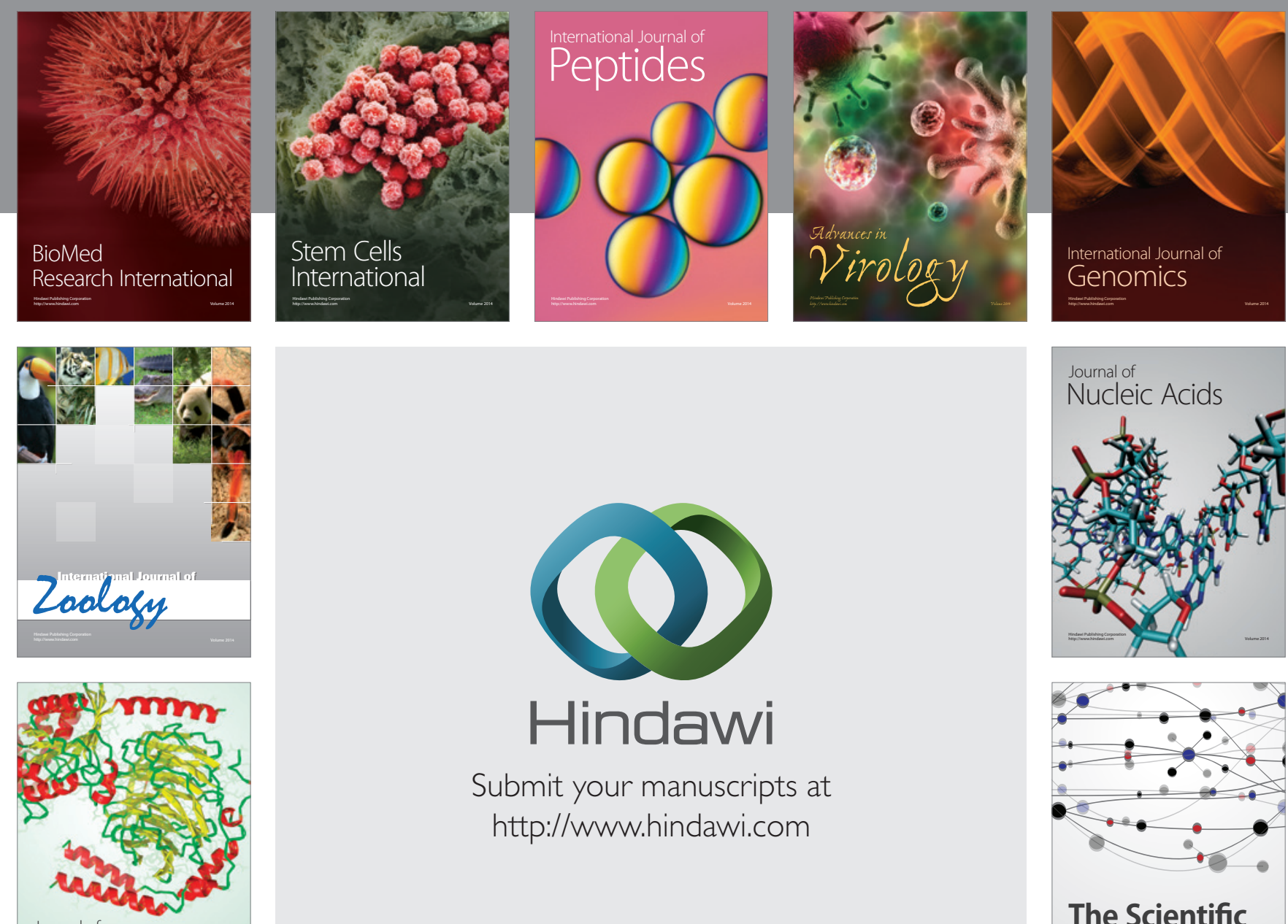

Submit your manuscripts at

http://www.hindawi.com

Journal of
Signal Transduction
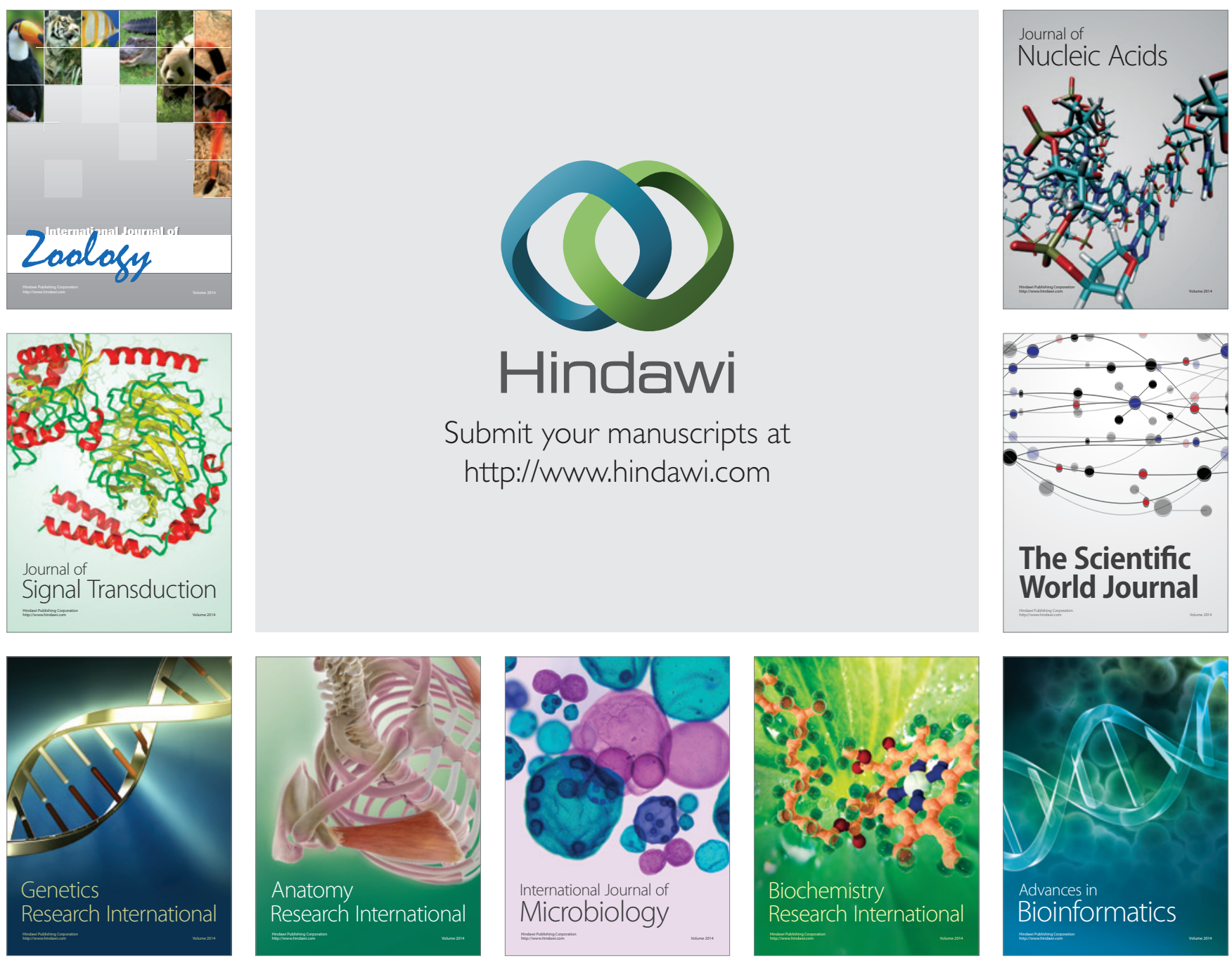

The Scientific World Journal
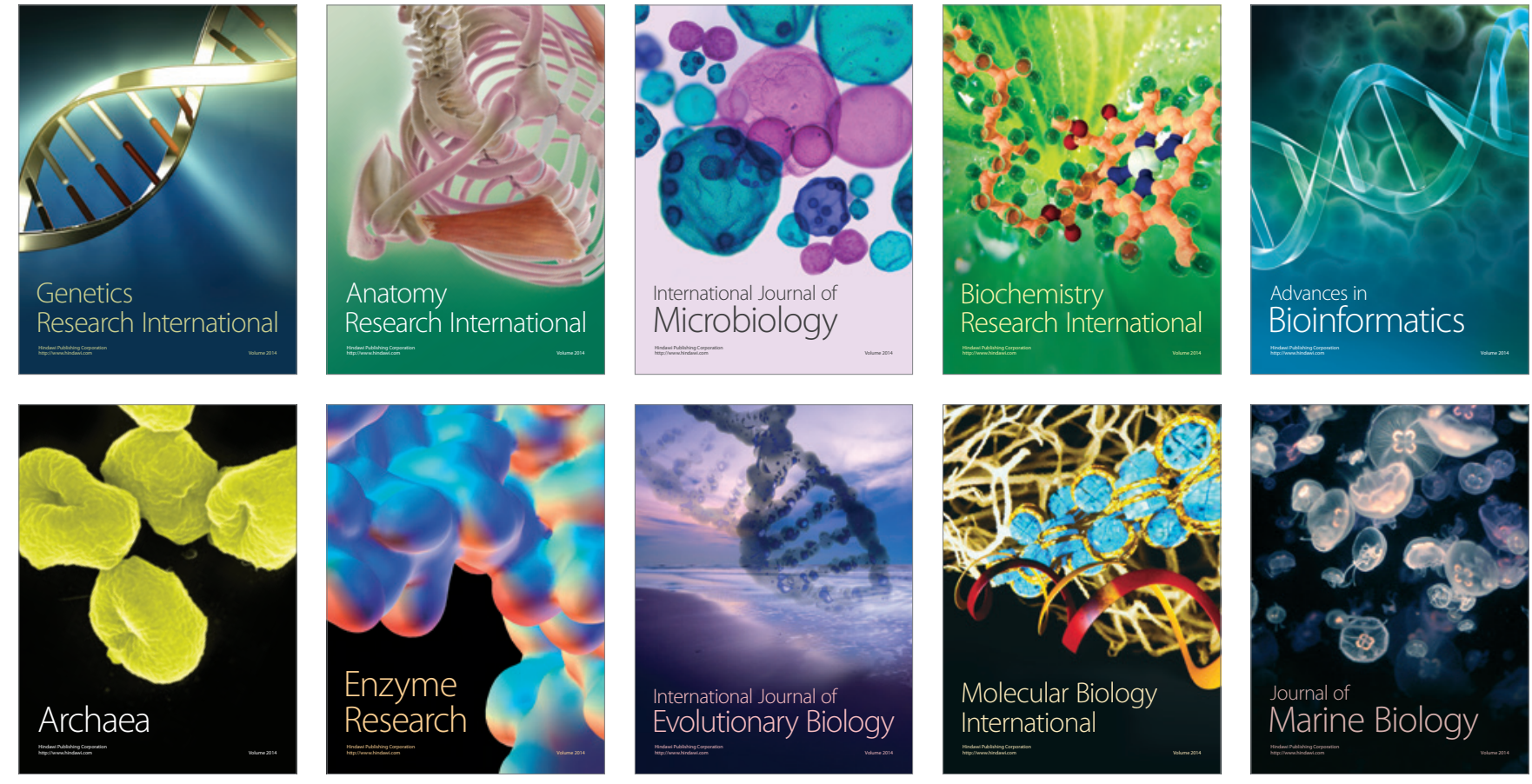